\title{
Access to the crista galli and the foramen caecum in nasal dermal sinus cysts - lessons learned in a single tertiary care centre*
}

\author{
Domenic Vital' ${ }^{1}$ Niklaus Krayenbühl'2, Oliver Bozinov², David Holzmann' \\ 'Dept. of Otorhinolaryngology, Head and Neck Surgery, University Hospital of Zurich, Switzerland \\ 2 Dept. of Neurosurgery, University Hospital of Zurich, Switzerland
}

Rhinology 51: 000-000, 2013 DOI:10.4193/Rhino12.158

*Received for publication: September 17, 2012

Accepted: January 5, 2013

\section{Summary}

Objective: Several surgical techniques have been suggested for the treatment of nasal dermal sinus cysts (NDSC). We have used several different techniques and have developed a minimally invasive approach. The aim of this study is to describe the evolution to this approach and compare the results with those achieved with our experience of more traditional techniques.

Methodology/Principal: A retrospective data collection of patients with NDSC presenting to our clinic between 1998 and 2012 was performed. We initially performed external approaches as outlined elsewhere. With an increasing number of young children requiring surgery, the technique was modified to a less invasive form. This new approach starts with mobilisation of the pit via a tiny skin incision. An open rhinoplasty approach is used to follow the fistula on the nasal bone. Once the fistula passes underneath the nasal bone, an endoscopic endonasal approach is used. Following the fistula cranially, the area of the foramen caecum can be identified.

Results: Twelve out of 15 patients (80\%) were treated surgically. The transfacial, coronal subcranial and minimally invasive approach was used in $3(25 \%), 4(33 \%)$ and 5 patients (42\%), respectively. Radical resection was achieved in all patients. Cosmetic problems were present in all patients undergoing a transfacial and in half of the patients after the coronal subcranial approach. Patients treated by the minimally invasive technique remained without sequelae.

Conclusion: The minimally invasive approach enables a perfect exposure of the fistula up to the crista galli and provides less morbidity and better cosmetic results than the transfacial and subcranial approach.

Key words: : nasal dermal sinus cyst, surgical approach, minimal invasive, treatment, skull base surgery

\section{Introduction}

Congenital nasal midline masses occur in 1 in 20,000 to 40,000 live births and can be divided according to their origin into ectodermal and neuroectodermal forms ${ }^{(1-3)}$. Neuroectodermal forms include meningoceles, meningoencephaloceles and nasal gliomas. Ectodermal forms include nasal dermoids and nasal dermal sinus cysts (NDSC). NDSC are defined as nasal dermal cysts associated with a sinus tract and a pit in the midline of the nasal dorsum or columella ${ }^{(4)}$. Accordingly, the term NDSC includes both items "sinus" and "cysts". In contrast, nasal dermoids are cystic lesions without a pit. They are treated by direct excision or an open rhinoplasty approach ${ }^{(5-9)}$. The approach for NDSC is still controversial. Several techniques have been suggested, including transfacial, open rhinoplasty and coronal approaches ${ }^{(5,8-14)}$.

Exposure and removal of the entire NDSC is the cornerstone of 
a successful treatment. As standard techniques cause significant sequelae like visible scarring and significant blood loss especially in children, we have attempted to develop a less invasive technique. The objective of this study is to outline the evolution of the approaches to the crista galli and our efforts to minimize the sequelae ${ }^{(15-18)}$. A minimally invasive approach to the crista galli and foramen caecum is described.

\section{Materials and methods}

Charts, CT and MRI scans of patients seen between 1998 and 2012 were retrospectively reviewed. Patients suffering from congenital nasal midline masses other than NDSC (e.g. nasal dermoids, nasal meningoceles and meningoencephaloceles) were excluded. Patients' data and symptoms were recorded (Table 1). All patients underwent radiological examination by computed tomography (CT). Intracranial extension of the NDSC was expected if the $\mathrm{CT}$ showed an enlarged foramen caecum and/or a bifid crista galli (Figure 1). Magnetic resonance imaging
(MRI) was added to depict the relation of the fistula with the anterior cranial fossa dura (Figure 2). Prophylactic perioperative cefuroxim was administered intravenously for the first 24 hours and then continued orally for another 5 days.

\section{The transfacial approach}

Up to 1999, patients with NDSC underwent a transfacial approach ${ }^{(18)}$. This technique starts with a Lynch incision, which is extended onto the nasal dorsum to the pit. By extracapsular dissection, the entire NDSC is excised. Osteotomies of the nasal bones became necessary in cases where the fistula had to be followed underneath the nasal bones. Similarly, osteotomies of the frontal bone were performed to follow the fistula up to the foramen caecum and crista galli.

\section{The coronal subcranial approach}

Due to visible scarring requiring surgical revision, the technique was modified to avoid facial incisions. From 2000 to 2006, the

Table 1. Patients characteristics.

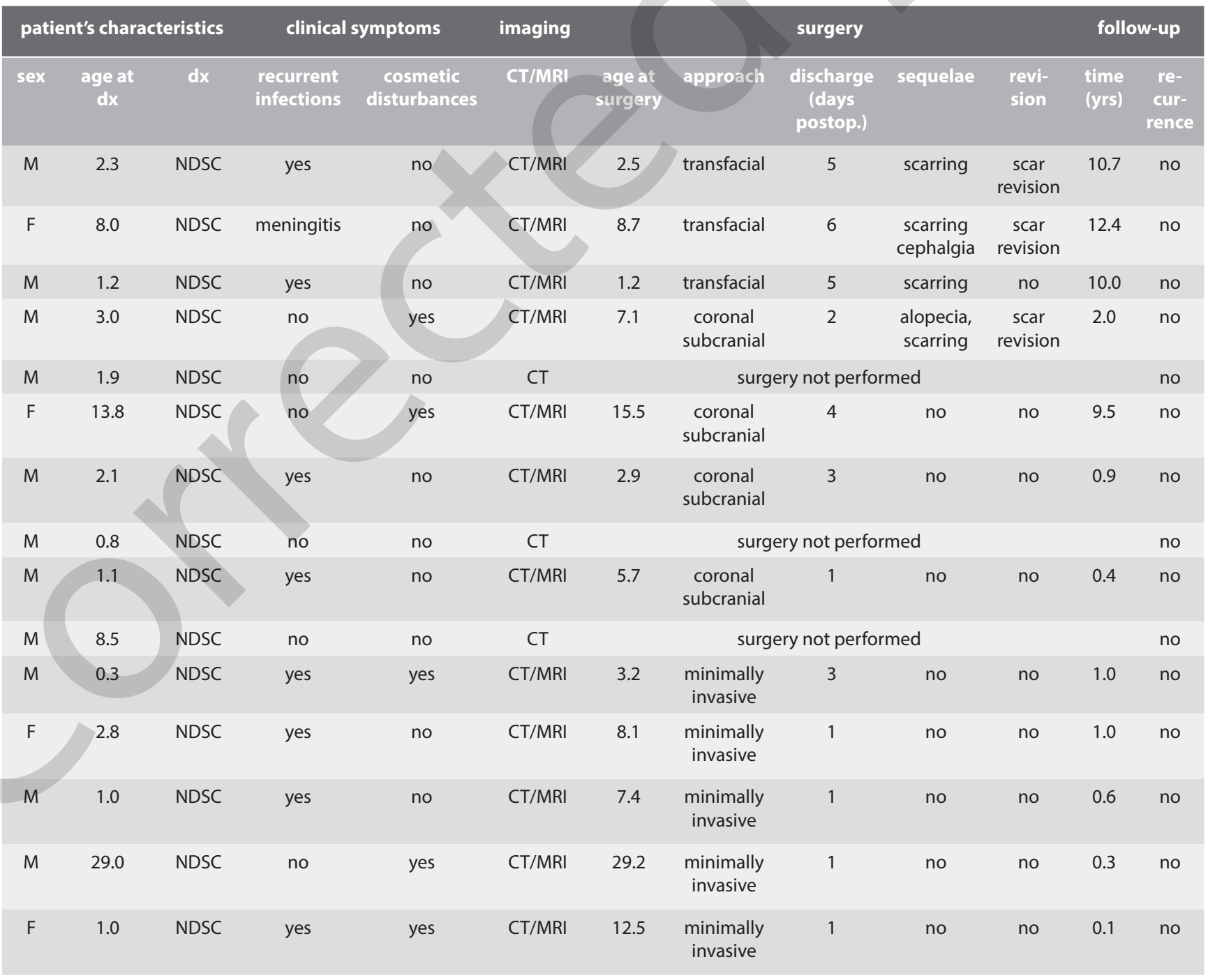




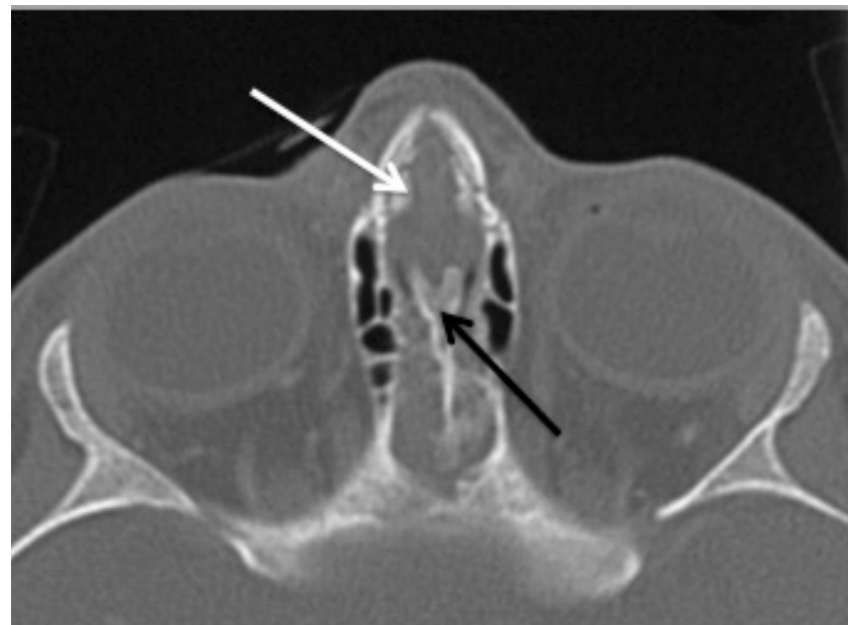

Figure 1. Axial slide of a CT scan showing the typical findings of an enlarged foramen caecum (white arrow) and a bifid crista galli (black arrow).

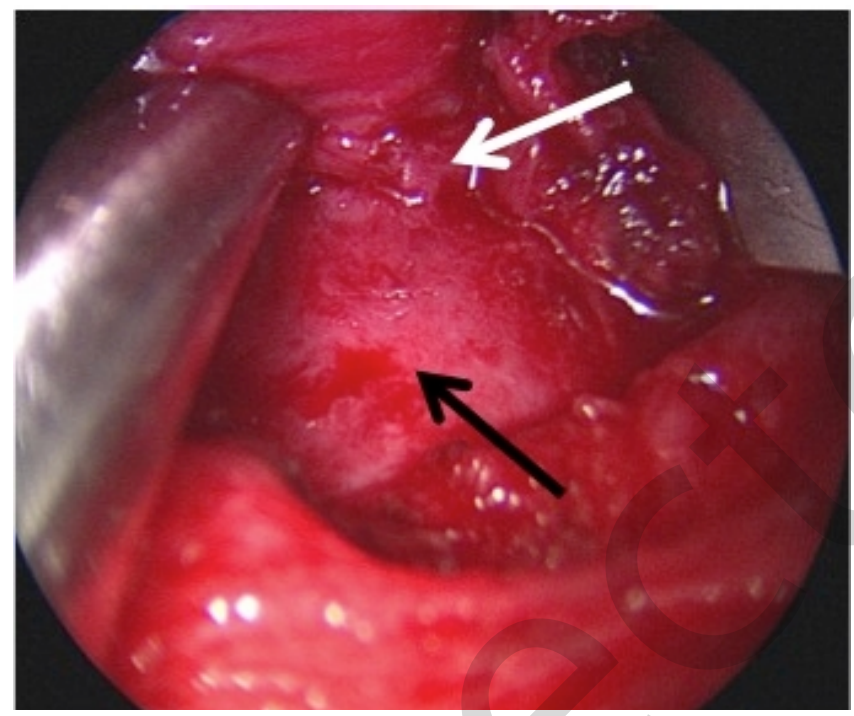

Figure 3. Intraoperative image, whereas the black arrow is indicating the bony nasal dorsum. The perforation of the nasal bones by the fistula tract is visible (white arrow).

coronal subcranial approach became our standard ${ }^{(18)}$. This technique starts with a mobilisation of the pit using small incisions. The cyst or sinus tract is mobilised by extracapsular dissection cranially as far as possible. To expose the most cranial portion, a coronal subcranial access down to the nasal dorsum was performed to identify the upper part of the mobilised fistula. Depending on whether the fistula continued in or underneath the nasal bone, osteotomies of the latter were performed. Following the fistula further up to the foramen caecum and crista galli, the inferior portions of the frontal bone had to be removed either using osteotomies or diamond drills ${ }^{(18)}$.

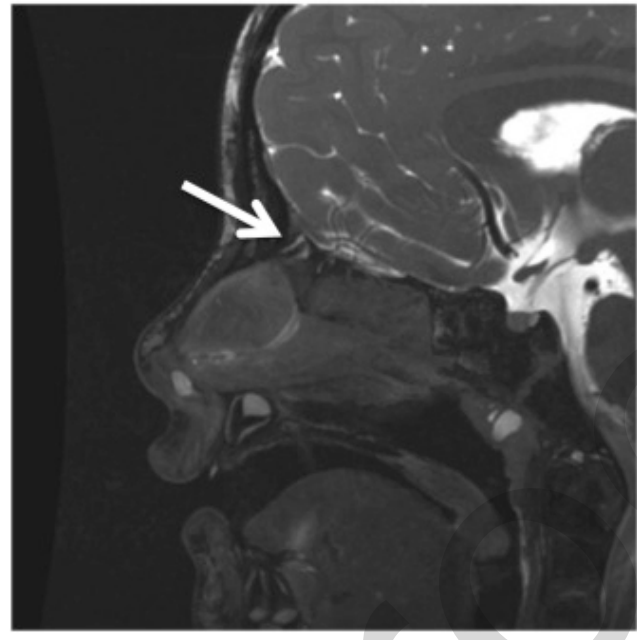

N

Figure 2.T2-weighted MRI indicating the close relationship of the fistula tract (white arrow) to the anterior cranial fossa dura.

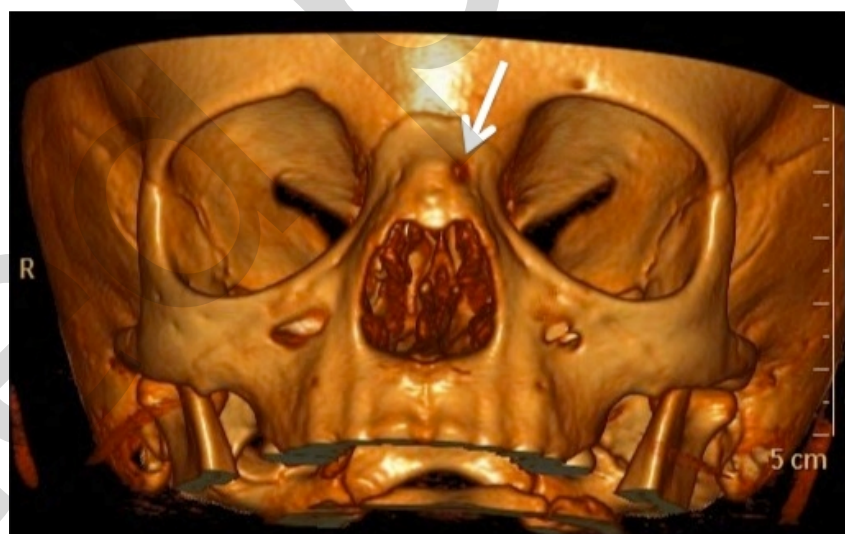

Figure 4. Three-dimensional CT reconstruction on which the perforation of the nasal bones (white arrow) is visible.
The minimally invasive approach

Similarly to the coronal subcranial approach, the combined endoscopic approach to the crista galli starts with mobilisation of the pit via a tiny skin incision and extracapsular dissection of the cyst or sinus on the nasal dorsum. Subsequently, an open rhinoplasty (transcolumellar) approach is performed to follow the fistula more cranially. This allows dissection of the fistula along the nasal dorsum up to the point where the fistula runs underneath or within the nasal bone (Figures 3 and 4). The more cranially located parts of the fistula are approached using an endonasal approach. This endoscopic dissection starts with a standard septoplasty technique. After a hemitransfixion incision, 


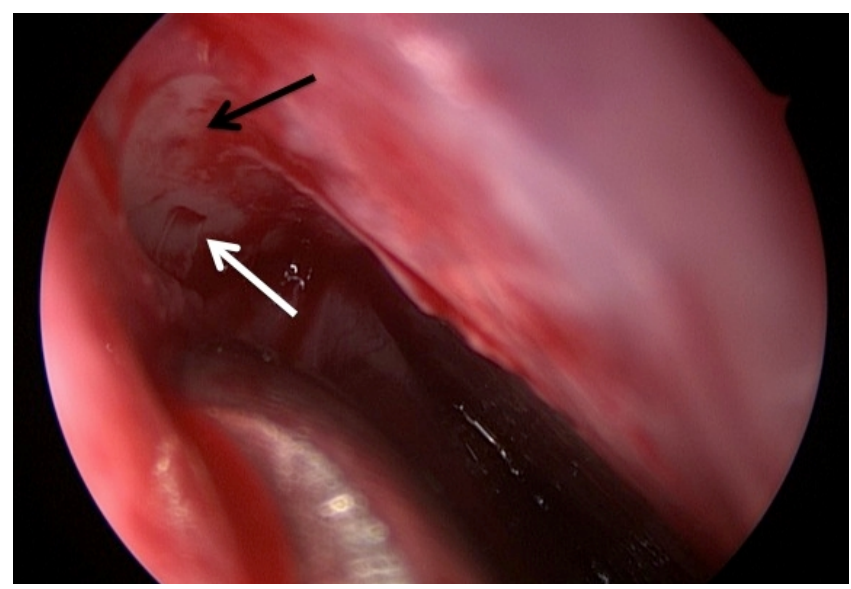

Figure 5. The black arrow is indicating the nasal bones shown from underneath. Identification of the fistula (white arrow) underneath the nasal bones at its place of perforation.

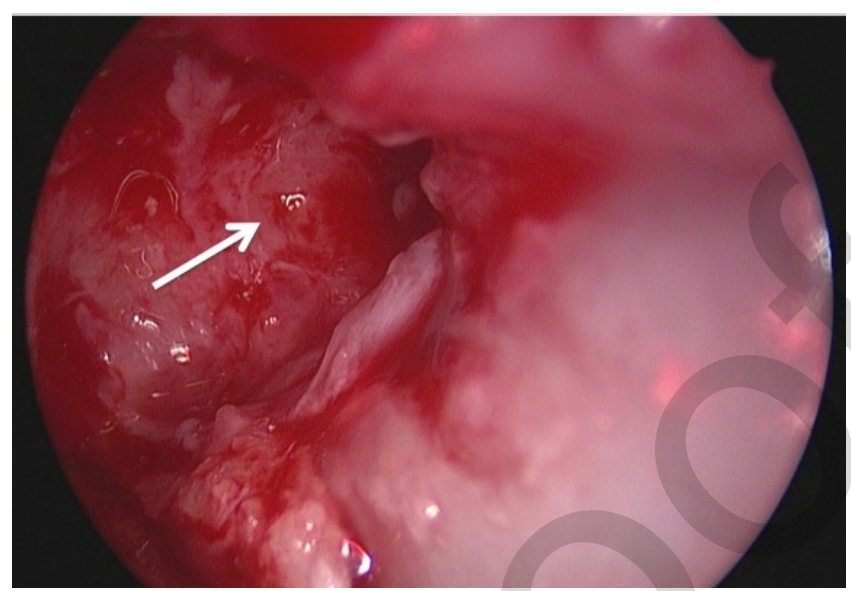

Figure 6. Intraoperative endoscopic image of the region of the foramen caecum (white arrow). the septal mucoperichondrium is mobilised up to the nasal dome. This allows identification of the fistula underneath the nasal bone and the fistula to be followed cranially up to the crista galli and the foramen caecum (Figure 5). Following the fistula cranially by extracapsular dissection, the area of the foramen caecum can be identified (Figure 6). Usually a collateral vein is found running through the foramen. If the foramen caecum is large, the pulsating anterior cranial fossa dura can be identified (Figure 7). The bone at the inferior and posterior edge of the foramen represents the anterior and inferior portion of the crista galli. Anteriorly and superiorly, the bony edge represents the bony groove of the superior sagittal sinus. In cases where the sinus tract went through the foramen caecum, the latter was slightly enlarged to expose the adjacent dura. None of the patients had a dural defect with CSF rhinorrhea. To cover the foramen caecum, the endonasal lining (i.e. the mucoperichondrium and mucoperiosteum) was mobilised and was swung back in its original position. To keep it in place, a resorbable packing with Spongostan ${ }^{\mathrm{TM}}$ (Johnson \& Johnson Medical, Norderstedt, Germany) was applied. Although not required in our series, dural sealing can be performed as described elsewhere ${ }^{(19)}$. Standard wound closure for septoplasty and open rhinoplasty is used.

\section{Results}

Between 1998 and 2012, 15 patients with NDSC presented to our hospital. Their characteristics are listed in Table 1. Mean age at diagnosis was 4.4 years $(0.1-29.0$ years). All patients presented with a pit on the nasal dorsum. Clinical symptoms leading to the diagnosis of a NDSC were cosmetic disturbances because of a mass on the nasal dorsum in 5 patients (33\%), recurrent suppurative infections of the fistula tract in 8 patients $(53 \%)$ and recurrent meningitis in 1 patient (7\%). The patient presenting with recurrent meningitis had two previous incomplete NDSC resections at another institution. CT examination was perfor- med in all patients and MRI examination in the 12 symptomatic patients (80\%) undergoing surgery. Surgery was performed at a mean age of 8.7 years $(1.2-29.2$ years). The transfacial, coronal subcranial and combined endoscopic approach was used in 3 (25\%), 4 (33\%) and 5 patients (42\%), respectively. Radical resection was achieved in all patients no matter which technique was used. None of the patients needed blood transfusions intra- or postoperatively. Suture removal had to be performed in general anaesthesia in all 3 patients with a transfacial and in 1 patient (25\%) with the coronal subcranial approach.

Significant scarring was present in 5 patients (42\%) of whom 3 patients (25\%) underwent a transfacial approach and 2 (17\%) a coronal subfrontal approach. Within our series, none of the patients presented with CSF-rhinorrhea. Only one girl (second patient in Table 1) developed recurrent meningitis after two incomplete transfacial resections of the fistula. Two (67\%) of the 3 patients with scarring after the transfacial approach required scar revision, one (33\%) of these patients furthermore suffered from chronic headaches. Two patients (50\%) after coronal subcranial approach suffered from a small area of alopecia on the scalp (Figure 8), which was surgically revised in one case (25\%). The small area of alopecia was due to a thermal injury caused by the diathermy dissection, which was abandoned consequently. At a mean follow up of 4.1 years ( $0.1-12.4$ years), none of the patients had recurrent disease.

\section{Discussion}

\section{Definition of NDSC}

Most publications on NDSC are case reports, small series of patients or reviews ${ }^{(5,10,12-14,20)}$. Larger published series either combined ectodermal and neuroectodermal masses or they summarized different malformations under the label of NDSC $(8,9,11)$. PubMed searching identified only three papers discussing the endoscopic treatment of NDSC ${ }^{(15-17)}$, while other articles focused 


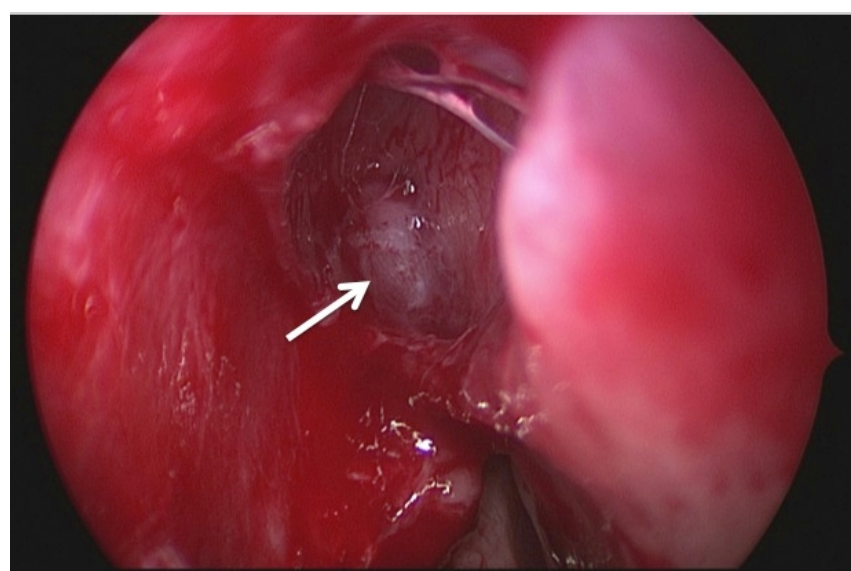

Figure 7. Endoscopic imaging showing the region of the foramen caecum with the anterior cranial fossa dura (white arrow).

on nasal dermoids ${ }^{(21-23)}$. However, before the surgical approach of choice is described, we must first precisely define the disease. Our study only includes patients with a pathognomic pit on the nasal dorsum, the columella or the upper lip connected with a sinus tract with cystic enlargement running cranially up to the foramen caecum as described by Session et al. ${ }^{(4,18)}$.

\section{Historical background of the surgical technique}

Some 30 years ago Pollock first attempted to systematically define criteria as to when to use which approach for nasal dermoids and NDSC ${ }^{(24)}$. He argued that the chosen approach should allow access to all midline cysts and enable lateral and medial osteotomies. Furthermore, it should be possible to repair cribriform defects and to reconstruct the nasal dorsum. Finally, the approach should be cosmetically acceptable and lead to minimal scarring. He described three approaches, which he felt fulfilled these criteria: the transverse rhinotomy, the vertical zig-zag rhinotomy and the tripod-eversion rhinotomy. All of these are transfacial techniques included the potential risk for cosmetically unacceptable scarring requiring revision.

Radical removal of the entire fistula is the cornerstone of any treatment of NDSC. No matter what kind of approach is used, the technique must enable exposure of the critical area of the foramen caecum and crista galli. In terms of exposing the malformation, its radical resection and the long-term outcome, both the transfacial approach and the coronal subcranial approach are adequate. However, even if incisions in the transfacial approach are done along the aesthetic units, visible scarring requiring revision surgery remains a significant problem. This problem could be significantly reduced by introducing the coronal subcranial approach. In a prior study, we demonstrated that this approach is feasible even in small children ${ }^{(18)}$. Despite its feasibility, the morbidity of this approach still remained high. The duration of the operation was higher than the time required

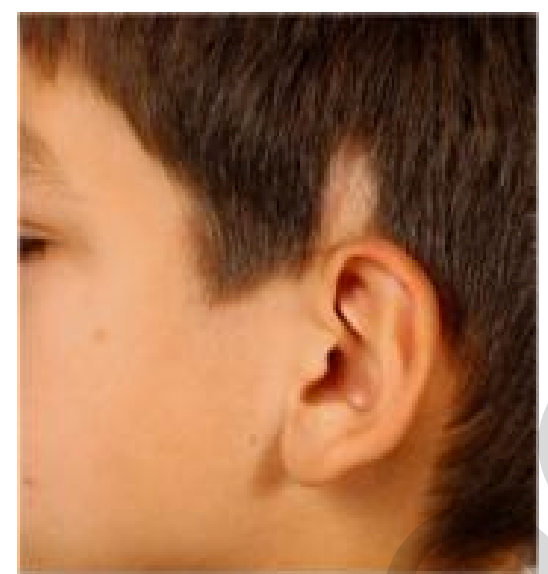

Figure 8. Small alopecia of the scalp in a patient after the coronal subcranial approach.

for a transfacial approach. Furthermore, the large galea flap and osteotomies of the frontal bone carried the risk of a haemodynamic relevant blood loss requiring transfusion. From an aesthetic point of view, the potential need of osteotomies in a growing skull is problematic and carries the risk to cause significant disfigurement of the nose, the face or the profile.

Lessons learned - why we changed the surgical approach We aimed to show the evolution of the techniques towards minimally disruptive endoscopic techniques. Fortunately, advances in endoscopic surgery of the frontal skull base allow an elegant approach to the crista galli and the feasibility of these techniques in small children has been demonstrated recently ${ }^{25-}$ 27). In recent years, we were confronted with some small children younger than 6 years of age in whom surgery was indicated. Facing the potential blood loss due to the subcranial access or visible scarring using the transfacial technique, we were forced to find other techniques to operate on smaller children. An advantage of our minimally invasive technique is significantly less blood loss in comparison to all coronal subcranial access procedures. A further important advantage is that the entire fistula can be exposed avoiding any osteotomies of the nasal bone. Osteotomies of the facial skeleton potentially may influence midfacial growth (in particular the nose), which may become evident many years after surgery.

Blood loss was the main reason why we convinced parents to delay surgery until the age of approximately 8 years whenever possible. In addition, we found some significant alopecia using the coronal incision. The transfacial approach was much less associated with significant blood loss. However, according to our experience with high risk of permanent visible scarring, this technique was no longer an option.

None of our patients had a dural defect with CSF rhinorrhea. However, because of the few cases treated by the minimally in- 
vasive technique until now, it is not possible to calculate the risk of a postoperative CSF leak. Regarding unpublished data and our experiences with reconstruction of dural defects of similar topography and extent, we estimate the risk of a postoperative CSF leak to be low. Whether the minimal invasive technique will be the surgical technique of choice will have to be proven with larger series and longer follow-up. Similar surgical techniques were proposed by Weiss et al. ${ }^{(17)}$ and Schuster et al. ${ }^{(15)}$.

\section{The role of pre-operative imaging}

It has to be taken into account that all patients with NDSC potentially have intracranial extension as has been shown on pre-operative imaging studies ${ }^{(3,8,11)}$. Radiologically, direct signs of intracranial extension include visible intracranial contents or signal alterations. Indirect signs include radiological findings of a bifid or deformed crista galli, an enlarged foramen caecum and/ or a dehiscence in cribriform plate ${ }^{(11,28)}$.

\section{Conclusions}

The minimally invasive combined endoscopic approach enables good exposure of the entire fistula from the nasal pit up to the crista galli and provides excellent cosmetic results, limiting external incisions to an absolute minimum and avoiding osteotomies of the nasal and the frontal bone. Further studies with larger numbers of patients and a longer follow-up are needed to examine the long-term results of the new approach.

\section{Acknowledgements}

We would like to express our gratitude to Mr. Thomas Pézier, MRCS, for his helpful editorial work and the proofreading of the manuscript.

\section{Authorship contribution}

Study concept and design: Vital and Holzmann. Acquisition of data: Vital and Holzmann. Analysis an interpretation of data: Vital, Krayenbühl, Bozinov and Holzmann. Drafting of the manuscript: Vital and Holzmann. Critical revision of the manuscript: Krayenbühl, Bozinov and Holzmann. Study supervision: Holzmann.

\section{Conflict of interest}

No conflict of interest.

\section{References}

1. Pratt LW. Midline cysts of the nasal dorsum: embryologic origin and treatment. Laryngoscope. 1965; 75: 968-980.

2. Hughes GB, Sharpino G, Hunt W, Tucker HM. Management of the congenital midline nasal mass: a review. Head Neck Surg. 1980; 2: 222-233.

3. Paller AS, Pensler JM, Tomita T. Nasal midline masses in infants and children. Dermoids, encephaloceles, and gliomas. Arch Dermatol. 1991; 127: 362-366.

4. Sessions RB. Nasal dermal sinuses--new concepts and explanations. Laryngoscope. 1982; 92: 1-28.

5. Rohrich RJ, Lowe JB, Schwartz MR. The role of open rhinoplasty in the management of nasal dermoid cysts. Plast Recontr Surg. 1999; 104: 1459-1466

6. Loke DK, Woolford TJ. Open septorhinoplasty approach for the excision of a dermoid cyst and sinus with primary dorsal reconstruction. J Laryngol Otol. 2001; 115: 657-659.

7. Paulose KO, al Khalifa S, Raj SS, Saeed T. Pilonidal sinus of the nose. J Laryngol Otol. 1989; 103: 1210-1213.

8. Bloom DC, Carvalho DS, Dory C, Brewster DF, Wickersham JK, Kearns DB. Imaging and surgical approach of nasal dermoids. Int J Pediatr Otorhinolaryngol. 2002; 62: 111-122.

9. Locke R, Rakhra J, Kubba H. A comparative study of two techniques for excision of midline nasal dermoids: how we do it. Clin Otolaryngol. 2011; 36: 252-255.

10. Kellman RM, Goyal P, Rodziewicz GS. The transglabellar subcranial approach for nasal dermoids with intracranial extension. Laryngoscope. 2004; 114: 1368-1372.

11. Denoyelle F, Ducroz V, Roger G, Garabedian EN. Nasal dermoid sinus cysts in children. Laryngoscope. 1997; 107: 795-800.

12. Hanikeri M, Waterhouse N, Kirkpatrick N Peterson D, Macleod I. The management of midline transcranial nasal dermoid sinus cysts. Br J Plast Surg. 2005; 58: 1043-1050.

13. Vaghela HM, Bradley PJ. Nasal dermoid sinus cysts in adults. J Laryngol Otol. 2004; 118: 955-962.

14. van Aalst JA, Luerssen TG, Whitehead WE, Havlik RJ. "Keystone" approach for intracranial nasofrontal dermoid sinuses. Plast Reconstr Surg. 2005; 116: 13-19.

15. Schuster D, Riley KO, Cure JK, Woodworth BA. Endoscopic resection of intracranial dermoid cysts. J Laryngol Otol. 2011; 125: 423-427.

16. Manning SC, Bloom DC, Perkins JA, Gruss JS, Inglis A. Diagnostic and surgical challenges in the pediatric skull base. Otolaryngol Clin North Am. 2005; 38: 773-794.

17. Weiss DD, Robson CD, Mulliken JB. Transnasal endoscopic excision of midline nasal dermoid from the anterior cranial base. Plast Reconstr Surg. 1998; 102: 2119 2123.

18. Holzmann D, Huisman TA, Holzmann P, Stoeckli SJ. Surgical approaches for nasal dermal sinus cysts. Rhinology. 2007; 45: 31-35.

19. Huber GF, Gengler C, Walter C, Roth T, Huber A, Holzmann D. Adenocarcinoma of the nasal cavity and paranasal sinuses: single-institution review of diagnosis, histology, and outcome. J Otolaryngol Head Neck Surg. 2011; 40: 34-39.

20. Pinheiro-Neto CD, Snyderman $\mathrm{CH}$, Fernandez-Miranda J, Gardner PA. Endoscopic endonasal surgery for nasal dermoids. Otolaryngol Clin North Am. 2011; 44: 981-987, ix.

21. Lachica RD, Wallace RD, Tsujimura RB. Case report: endoscopic excision of a nasoglabellar dermoid. J Craniofac Surg. 2004; 15: 473-477.

22. Lee S, Taban M, Mancini R, Chong K, Goldberg RA, Douglas RS. Endoscopic removal of nasoglabellar dermoid cysts. Ophthal Plast Reconstr Surg. 2010; 26: 136139.

23. Düz B, Secer HI, Tosun F, Gonul E. Endoscopic endonasal resection of a midline intradural frontobasal dermoid tumour. Minim Invasive Neurosurg. 2007; 50: 363366.

24. Pollock RA. Surgical approaches to the nasal dermoid cyst. Ann Plast Surg. 1983; 10: 498501.

25. Lee JM, Ransom E, Lee JY, Palmer JN, Chiu AG. Endoscopic anterior skull base surgery: intraoperative considerations of the crista galli. Skull Base. 2011; 21: 83-86.

26. Kassam A, Snyderman CH, Mintz A, Gardner P, Carrau RL. Expanded endonasal approach: the rostrocaudal axis. Part I. Crista galli to the sella turcica. Neurosurg Focus. 2005; 19: E3.

27. Holzmann D, Bozinov O, Krayenbühl N. Is 


$$
e^{e^{e^{e^{e}}}}
$$

